\title{
The use of the Morse Fall Scale in an acute care hospital
}

\author{
Barbara J. Watson*1, Alan W. Salmoni², Aleksandra A. Zecevic ${ }^{2}$ \\ ${ }^{1}$ Health \& Rehabilitation Sciences, Western University, London, Canada \\ ${ }^{2}$ School of Kinesiology, Western University, London, Canada \\ ${ }^{3}$ School of Health Studies, Western University, London, Canada
}

Received: January 17, 2016

DOI: $10.5430 /$ cns.v4n2p32
Accepted: February 14, $2016 \quad$ Online Published: February 29, 2016

URL: http://dx.doi.org/10.5430/cns.v4n2p32

\begin{abstract}
Background: Patient falls in hospitals account for a high proportion of adverse events. Assessing patient risk is a vital part of a fall prevention program. When a fall risk assessment tool is used, it is imperative to use one which is suitable for the hospital. Objective: The purpose of this study was to test the predictive validity of the Morse Fall Scale (MFS) by assessing the sensitivity, specificity, positive predictive value (PPV) and negative predictive value (NPV) on medicine units in an acute care hospital.

Methods: Patient MFS scores were obtained from the medicine units. A total of 500 patient scores were collected along with a number of falls which occurred within 7 days of the fall risk assessment. Data were collected from November 2014 to March 2015. The setting was a large teaching hospital located in Ontario, Canada.

Results: Using a cut-off point of 25 on the MFS, the sensitivity was $98 \%$ and the specificity was $8 \%$. The PPV was $10 \%$ and the NPV was 97\%. An MFS cut-off point of 55 provided the most balanced measure of sensitivity (87\%) and specificity (34\%) for accurate identification of fall risk.

Conclusions: Findings suggest a change in practice is warranted as the values showed a poor balance between the sensitivity and specificity range. Recommendations for changes in practice include: changing the screening tool cut-off point from 25 to 55 , or removing the use of a screening tool and assessing the risk by using another method.
\end{abstract}

Key Words: Patient falls, Falls prevention programs, Falls risk assessment tools

\section{INTRODUCTION}

Up to $84 \%$ of adverse events in hospitals are related to falls. Thirty percent of these falls cause injuries including serious injuries and death. ${ }^{[1]}$ Healthcare quality improvement organizations such as Accreditation Canada, the Registered Nurses Association of Ontario, the Canadian Institute for Health Information and the Canadian Patient Safety Institute have declared that falls jeopardize patient safety and have recommended practice standards to include a fall prevention program in hospitals. ${ }^{[2-4]}$ With a growing older population, falls will continue to be a major concern for hospital staff and administrators. Fall rates can be as high as 11.5 per 1,000 patient days in hospitals. ${ }^{[5,6]}$ Patient falls account for a substantial amount of physical and psychological harm, functional decline, prolonged length of hospital stays and increased costs. ${ }^{[7]}$ Approximately $10 \%$ to $25 \%$ of older patients fall during their hospital stay. ${ }^{[8,9]}$ The World Health Organization (WHO) at its first World Congress for Healthy

*Correspondence: Barbara J. Watson; Email: bwatson3@uwo.ca; Address: Health \& Rehabilitation Sciences, Western University, London, ON, N6G 1H1, London, Canada. 
Ageing deemed falls a "geriatric giant", a term first coined by Bernard Isaacs and is used to illustrate the immense problem related to falls. ${ }^{[10]}$ This safety threat has mandated the need for an effective fall prevention program.

Fall prevention programs start with an assessment for patient risk using a screening tool specifically designed for hospitalized patients. ${ }^{[11-13]}$ There are several fall risk assessment screening tools developed for hospital settings, however, none have consistently high predictive validity. ${ }^{[14]}$ Choosing the correct tool takes careful deliberation to find the one best suited for the particular hospital program, since one hospital setting can be different from another with their own unique medical specialties and patient populations. ${ }^{[1,15]}$ Although it is recommended to ask risk questions at the time of admission, such as has the patient previously fallen, ${ }^{[16,17]}$ some other risk factors associated with falls may not be evident at this time. The inability to score mobility, assess medication treatments and screen for cognitive decline are examples of risk factors that staff may not be able to assess at the time of admission. Other situations such as an aging patient population may pose a higher falls risk than a falls risk score indicates. For example, a study by Chelly et al. ${ }^{[18]}$ found that patients over the age of 55 fell more frequently than patients under the age of 55; and an 80 year old patient had 3 times more risk of a fall resulting in injury than a 50 year old patient on the same ward. Inversely, patients scoring high on the screening tool may experience an improvement in health and require less attention than first identified by the risk assessment. Patient conditions and fall risk fluctuate during a hospital stay. ${ }^{[11]}$

Morse and her colleagues have written several articles on the "fall-prone patient" and the use of the Morse Fall Scale (MFS) screening tool to identify patients at high risk. ${ }^{[16]}$ In Morse's view, some falls can be prevented and the MFS was an appropriate screening tool to identify fall risk. To develop the MFS, Morse et al. ${ }^{[19]}$ conducted a study with 100 fallers and 100 non-fallers as a control group. Stepwise discriminant analysis was used to determine the six subscales used in the MFS. The authors found that $25 \%$ of participants in the fallers group had previously fallen, $32 \%$ were disoriented and patients in the fall group were more likely to have an intravenous (IV) device. Mobility problems requiring gait aid were also a significant factor in the fall group. With 45 as the cut-off point, the sensitivity was $78 \%$ and the specificity was $83 \%$. Morse et al. ${ }^{[20]}$ were able to validate the MFS in acute care, long-term and rehabilitation clinical areas. They analyzed the type of patient falls that occurred over a 4-month period. They found that the scores from the MFS correlated with the risk for falling and severity of injuries sustained from the falls. However Morse asserts that each hospital unit should carry out a pilot project to determine the best sensitivity and specificity for their population but stay within the 25-55 cut-off range. Morse stresses that in acute care hospitals, a risk score as low as 25 can be acceptable since some areas may only have high risk patients and all fall prevention strategies should be in place in order to protect this group. ${ }^{[16]}$

Scott $e t$ al. ${ }^{[14]}$ conducted a systematic review of studies that looked at the suitability of various fall risk assessment tools. Their study included screening tools used in the community and home support as well as in long-term and acute care hospitals. For the acute care hospital setting, they reviewed 12 studies using 8 different screening tools (Berg balance, Conley scale, Downton index, Elderly mobility scale, Fallrisk assessment, Functional reach, MFS and the STRATIFY). They measured the predictive validity of these tools which included a sensitivity and specificity analysis. According to their findings, two fall risk assessment tools rated over $70 \%$ for both sensitivity and specificity (Schmid-sensitivity 93\%, specificity 78\%; STRATIFY-sensitivity 93\%, specificity $88 \%)$. Scott et al. ${ }^{[14]}$ recommended validating fall risk assessment tools in all settings including acute care hospitals by analyzing sensitivity, specificity, positive predictive value (PPV) and negative predictive value (NPV) values, as well as using a Receiver Operating Characteristic (ROC) curve analysis to select the optimal cut-off point. Other considerations that were revealed in this study were the amount of time it took for completing the screening tool, how much equipment was needed and what kind of training was necessary.

A study by Ang et al. ${ }^{[21]}$ in Hong Kong evaluated three different fall risk assessment tools used in an acute care hospital. The analysis was based on the predictive values of sensitivity, specificity, PPV, NPV and inter-relater reliability. The study concluded that the Hendrich II Fall Risk Model (HFRM) was more effective in the hospital setting than the MFS or the St. Thomas Risk Assessment Tool in Falling Elderly Inpatients (STRATIFY). The predictive validity of the HFRM was rated high for both sensitivity (70\%) and specificity $(61.8 \%)$ with a cut-off of 5 in their study. The HFRM was developed to be used in hospitals ${ }^{[22]}$ and has categories related to geriatric conditions (history of falls, altered elimination, confusion/disorientation, depression, dizziness, poor mobility/weakness and poor judgment).

In another study by Aranda-Gallardo et al. ${ }^{[1]}$ the STRATIFY was viewed as a more useful fall prevention screening tool than the HFRM and MFS. They conducted a systematic review and meta-analysis of fall risk assessment tools, ultimately examining 14 research articles assessing predictive validity. Comparing the MFS, STRATIFY and HFRM 
they found that the STRATIFY more accurately predicted patient falls in an acute care hospital. The STRATIFY fall risk tool is short and has 5 items addressing previous falls, agitation, visual impairment, frequent toileting and mobility issues. The predictive validity scores for sensitivity (93\%) and specificity ( $88 \%$ ) were high when it was tested in the original setting. ${ }^{[23]}$

Another study by Baek et al. ${ }^{[15]}$ conducted in Korea validated the MFS in a hospital setting. The authors accessed falls information from the patients' electronic chart. There were 151 fallers and 694 non-fallers during the study period. The MFS score data were collected at three different points in time. The scores were collected from admission, the last score and the highest score. The results showed high sensitivity (72\%) and high specificity (91\%) when the cut-off point was 51. ${ }^{[15]}$

The contrasting findings in these studies confirm that screening tools need to be tested in each setting prior to use due to the diversity in patient populations and the hospital environments. ${ }^{[24]}$ Ang et al. ${ }^{[21]}$ found the HFRM to be most effective for identifying patients at risk for falling. ArandaGallardo et al. ${ }^{[1]}$ found the STRATIFY to be most effective for identifying patients at risk for falling. Baek et al. ${ }^{[15]}$ found the MFS to be most effective for identifying patients at risk for falling. These findings also suggest that a periodic analysis of a tool's effectiveness is warranted.

The present acute care hospital adopted the MFS in 2007 in order to assess patient fall risk and to use the assessment to initiate fall prevention strategies. To date the choice of the MFS had not been validated. The purpose of this study was to test the predictive validity of the MFS by assessing the sensitivity, specificity, PPV and NPV on the medicine units in an acute care hospital. The scale's cut-off point was assessed to determine its potential effect on the predictive validity of the scale.

\section{MethodS}

\subsection{Research design}

The study was a cross-sectional prospective emergent design consisting of both quantitative and qualitative measures. The quantitative analysis used MFS scores to evaluate the predictive validity of the MFS fall risk screening tool. The qualitative analysis examined the views and experiences emanating from the use of the MFS screening tool by hospital staff in their everyday clinical practice. Emergent design allows a study to unfold and develop in the course of the research to provide a richer interpretation of the data. ${ }^{[25]}$ Surveys were given to the Continuous Quality Improvement (CQI) staff to gather their perspectives on the scale's util- ity. This study did not require approval by the hospital's Research Ethics Board since it was a quality improvement initiative which used un-identified secondary data.

\subsection{Setting}

The setting for the study was medicine units in a large acute care teaching hospital located in Ontario, Canada. The hospital is a multisite facility which has more than one million patient visits per year. The falls per 1,000 patient days was 4.4 in the last five years for the whole hospital and the Medicine Program had a fall rate over 6.0 patient falls per 1,000 patient days. ${ }^{[26]}$ The Medicine Program is made up of different units ranging from subacute to higher acuity units.

\subsection{Participants}

Quantitative. Participants were adult patients aged 18 years and over who were admitted or transferred to a medicine unit. The average age of patients in the Medicine Program was 65 years old and common diagnoses included chronic obstructed pulmonary disease, congestive heart failure and diabetes.

Qualitative. The RNs taking part in the survey had 3-5 years of experience administering the MFS screening tool to patients. They worked on different medicine units in full-time nursing positions, were mainly female ( $\mathrm{n}=6$ female, $\mathrm{n}=1$ male) and were selected from the Medicine Program's CQI council.

\subsection{Assessment and recording of fall risk}

The MFS for predicting falls risk was developed by Morse in Alberta, Canada in 1985. It is composed of six subscales where each subscale identifies situations that put patients at higher risk for falls. ${ }^{[19]}$ The subscales are:

(1) History of falling (produced a score of 25 for "yes" to a fall and 0 score for "no"): A history of falling was coded if the patient had a fall 3 months prior to admission/transfer to the unit. One example was a patient who recalled falling on a slippery floor at home 3 months prior to admission to the hospital.

(2) Secondary diagnosis (produced a score of 15 for "yes" and 0 score for "no"): A secondary diagnosis was coded if the patient had more than one medical diagnosis listed in the patient's chart. An example was a patient diagnosed with renal failure who also had a previous stroke.

(3) Ambulatory aid (produced a score of 30 for "using furniture", 15 for "crutches/cane/walker/wheelchair/needs assistance", and 0 for "no/bedrest"): Ambulatory aids were coded if they were required for mobility. A patient could need an ambulatory aid if the nurse noticed 
him/her grasping tables and other furniture as they walked.

(4) IV/saline lock (produced a score of 20 for "yes" and 0 score for "no"): IV therapy was coded if the patient had a continuous IV or a saline lock for intermittent IV therapy. For instance, when a patient was getting intermittent IV antibiotic medication which required a saline lock device in his/her hand.

(5) Gait/transferring (produced a score of 30 for "yes" and 0 for "no"): Gait was assessed for normal, weak or impaired gait which needed higher assistance. An example was a patient with a decreased level of mobility who required assistance to transfer from the bed to a chair.

(6) Mental status (produced a score of 15 for "overestimates/forgets" and 0 for "oriented"): Changes in mental status could be a patient in a delirium state who was at a higher risk due to poor judgment.

The total possible score on the MFS is 125 . In the original study, Morse found that a cut-off score of 45 correlated with a high fall risk and recommended that a cut-off point should not exceed 55. ${ }^{[16]}$ Cut-off point refers to the score which the hospital has deemed acceptable to carry on with routine fall prevention strategies. Reaching the high risk score alerts staff to implement advanced strategies along with the standard care already put in place to prevent falls. For this study, the hospital chose to have a cut-off score of 25 as the point between low and high risk. Low risk $(<25)$ meant standard fall procedures such as call bell in place, adequate lighting, bed at lowest level with brakes on, and to ensure that non-slip footwear was available. Additional interventions for a score of 25 or greater included a bed exit alarm, high risk bracelet and a sign over the patient's bed identifying the risk level. Nursing staff assessed adult inpatients using the MFS on admission to the hospital, after every transfer from one unit to another within the hospital, weekly on Thursday, after a fall and if there was a change in medical condition. The MFS score was documented in the patient's bedside chart.

Falls were defined as events that result in a person unintentionally coming to rest on the ground or other lower level. ${ }^{\text {[27] }}$ In this study a faller was defined as a patient who experienced a fall within 7 days of an admission or transfer to the Medicine Program. Admissions meant patients coming directly from the Emergency Department, whereas transfers were movement from one hospital unit to another unit.

\subsection{Data collection}

\subsubsection{Quantitative}

The MFS data were collected in two stages from November 2014 to March 2015. The first stage consisted of gather- ing the MFS scores from the patient's bedside chart. The initial MFS score for each patient was extracted from the score for each of the six MFS subscale items. The second stage consisted of a follow-up to identify patients who experienced a fall within 7 days of the initial admission/transfer score. This was chosen because the MFS would be rescored 7 days after the admission/transfer which left room for changes in scoring and uncertainty. ${ }^{[28]}$ Data on fall occurrences were collected using three sources: (1) from the hospital's adverse event management system (AEMS), a computerized incident reporting system where staff reported adverse events within 24 hours of the incident; (2) nursing documentation notes in patient charts; and (3) from the self-report by nursing staff. The actual fall may have been witnessed (seen by staff) or unwitnessed. All nursing and other interdisciplinary staff (physiotherapists, occupational therapists, speech-language pathologists, registered dietitians, social workers and personal support workers) on the medicine units were provided with information on the research study and informed that the MFS scores would be collected from bedside charts.

\subsubsection{Qualitative}

Participants in the written interview were seven nurses from the Medicine Program's CQI council. The medicine CQI council is part of the hospital's larger inter-professional CQI group that is committed to implementing initiatives to improve patient and staff safety. The CQI council was chosen because of its mandate to improve patient care and increase staff satisfaction. A convenience sample of nurses were invited to participate $(n=10)$. The survey was handed out during a CQI council meeting. Questions posed to them were:

(1) In your opinion, is the MFS a useful tool in the hospital's fall prevention program? Explain why it is or is not.

(2) Could the MFS be improved? (If "yes", how could it be improved?)

(3) Are there other strategies that could be used to improve fall prevention?

A PowerPoint presentation of the quantitative results i.e., sensitivity and specificity findings was made prior to handing out the survey. Seven questionnaires were returned to the researcher anonymously by placing it in a marked folder.

\subsection{Data analysis}

Statistical analysis was carried out by using the SPSS version $22.0^{[29]}$ and by hand calculations using the following equations with the hospital's cut-off point of 25 (see Table 1): 
Sensitivity refers to testing the tool's ability to obtain a "true positive". This is the percentage that identifies the patients who fell that were predicted to fall (identified as high risk). Specificity tests the tool's ability to obtain a "true negative". This is the percentage of the patients who did not fall and were not predicted to fall (identified as low risk). The PPV shows the likelihood that a person testing positive for the risk of falling will actually have a fall. The NPV shows the likelihood that a person testing negative for the risk of falling will not fall. ${ }^{[30,31]}$ The cut-off point is where a decision is made as to whether or not a person has a risk of falling. This value separates the lower risk fallers from those higher risk fallers who require more fall prevention strategies. The ROC analysis was used to illustrate how accurate the MFS was for predicting falls in this hospital. This statistical test plots true positive (sensitivity) frequencies and true negatives (specificity) frequencies which then calculates other possible values that generates the ROC curve. The graphic picture of values related to the true positives and the false positives help determine if a test is accurate. The analysis can lead to an optimal cut-off value and determine the ability of the MFS to discriminate between patients at risk for falling and those that are not. The point closest to the left-hand corner represents the greatest discriminative point on the graph as in Figure 1. The maximum for this analysis is AUC equal to 1 which describes a strong screening tool to distinguish between patients with risk for falling and those not at risk. An AUC level close to 0.5 describes a chance risk using the screening tool, while an AUC close to 0 indicates incorrect classifications with patients classified as low risk and non-fallers classified as high risk. ${ }^{[32]}$ It is important to determine the optimal point which distinguishes the different cut-off points for patients putting them in either the risk for falling or not at risk. The optimal point is usually where the sensitivity and specificity are at their highest $(0,1)$ on the curve. ${ }^{[11,33]}$ When the cut-off point is high with a high specificity value, sensitivity is lost and patients at risk may be missed. When the cut-off point is lower producing a higher sensitivity value, more patients could be mistakenly deemed as high risk. Along with these data analyses, two researchers reviewed the responses of the surveys together and common themes were identified. Both researchers had extensive knowledge of the MFS screening tool and one had experience using the MFS screening tool in clinical practice. The themes that emerged were brought back to the CQI council for clarification and to ensure they reflected the nurses' views and experiences.

Table 1. Equations with the hospital's cut-off point

\begin{tabular}{lll}
\hline & Had a fall & Did not have a fall \\
\hline Predicted to fall & A (True positive) & B (False positive) \\
Not predicted to fall & C (False negative) & D (True negative) \\
Calculations: & \\
Sensitivity = A/A+C (True positive/True positive + False negative) \\
Specificity=D/B+D (True negative/False positive + True negative) \\
PPV=A/A+B (True positive/True positive + False positive) \\
NPV=D/C+D (True negative/False negative + True negative)
\end{tabular}

\section{RESUltS}

From November 19, 2014 through March 4, 2015 there were 508 MFS scores collected. Eight scores were excluded due to repetition (same patient transferring within the Medicine Program), leaving a total of 500 scores in the study (238 female and 262 male patients). There were 174 patients below the age of 65 and 326 were 65 years or older. Within the 7 days of admission/transfer onto a medicine unit there were 46 patients who fell. The mean age of the fallers was 68 (range: 18-100 years of age). Gait/transferring problems, having a secondary diagnosis and patients requiring an ambulatory aid were the top indicators checked off as shown in Table 2 . With the cut-off score of 25 , there were 37 who scored as a low fall risk and 463 who scored as a high fall risk. As shown in Table 3, the sensitivity was calculated as $98 \%(45 / 45+1)$ and the specificity was calculated as $8 \%(37 / 417+37)$.

The ROC curve, as shown in Figure 1, represents all falls collected during the study. The point closest to one $(0,1)$ depicting the overall ideal sensitivity and specificity point in the tool shows a cut-off point of 55 representing $87 \%$ sensitivity and 34\% specificity. An AUC percentage of 65 (95\% CI $0.575-0.719, p<.05)$ demonstrates that the MFS has a weak predictive validity to discriminate between patients with falls risk and those not at risk..$^{[9,11,33]}$

Table 2. Summary of risk factors on 6 sub-scales of MFS

\begin{tabular}{lllll}
\hline Risk Factors & n (Total = 500) & Percent & n (Fallers = 46) & Percent \\
\hline History of falling & 215 & 43 & 27 & 59 \\
Secondary diagnosis & 404 & 81 & 41 & 89 \\
Ambulatory aid & 323 & 65 & 39 & 85 \\
Intravenous/Saline lock & 472 & 94 & 38 & 83 \\
Gait/transferring & 362 & 72 & 42 & 91 \\
Mental status & 177 & 35 & 15 & 33 \\
\hline
\end{tabular}

Note. MFS's 6 sub-scale indicators and the number and percentage patients scored on each of the items 
Table 3. MFS Predictive values and cut-off scores

\begin{tabular}{|c|c|c|c|c|c|c|c|c|c|c|c|c|c|c|}
\hline \multirow{2}{*}{$\begin{array}{l}\text { Predictive values } \\
\text { Cut-off Points }\end{array}$} & \multicolumn{14}{|c|}{ Scores $(n=500)$} \\
\hline & 25 & 10 & 20 & 30 & 40 & 50 & 55 & 60 & 70 & 80 & 90 & 100 & 110 & 120 \\
\hline Sensitivity \% & 98 & 0 & 0 & 98 & 93 & 91 & 87 & 87 & 70 & 52 & 28 & 7 & 2 & 0 \\
\hline Specificity \% & 8 & 1 & 3 & 9 & 19 & 27 & 34 & 39 & 54 & 67 & 83 & 64 & 94 & 100 \\
\hline PPV \% & 10 & 0 & 0 & 10 & 10 & 11 & 12 & 13 & 13 & 15 & 15 & 7 & 3 & 0 \\
\hline NPV \% & 97 & 100 & 100 & 98 & 97 & 97 & 96 & 97 & 95 & 94 & 92 & 70 & 90 & 100 \\
\hline
\end{tabular}

Note. The cut-off points estimations for sensitivity, specificity, PPV and NPV $(n=500)$; A cut-off point of 55 is recommended

Table 4. MFS study questionnaire themes

\begin{tabular}{|c|c|}
\hline Themes & Comments \\
\hline \multirow{3}{*}{ Change or adjust screening tool } & "Increase the high falls risk score" \\
\hline & “Add an unsteady section” \\
\hline & "I find staff complain it is just more paperwork and just check them all off" \\
\hline \multirow{3}{*}{ Education } & "Provide specific steps to prevent falls” \\
\hline & "Unit specific analyzing of individual fall in [the hospital] based on available data” \\
\hline & "[We need to be] looking [at the] primary root causes of fatal falls" \\
\hline
\end{tabular}

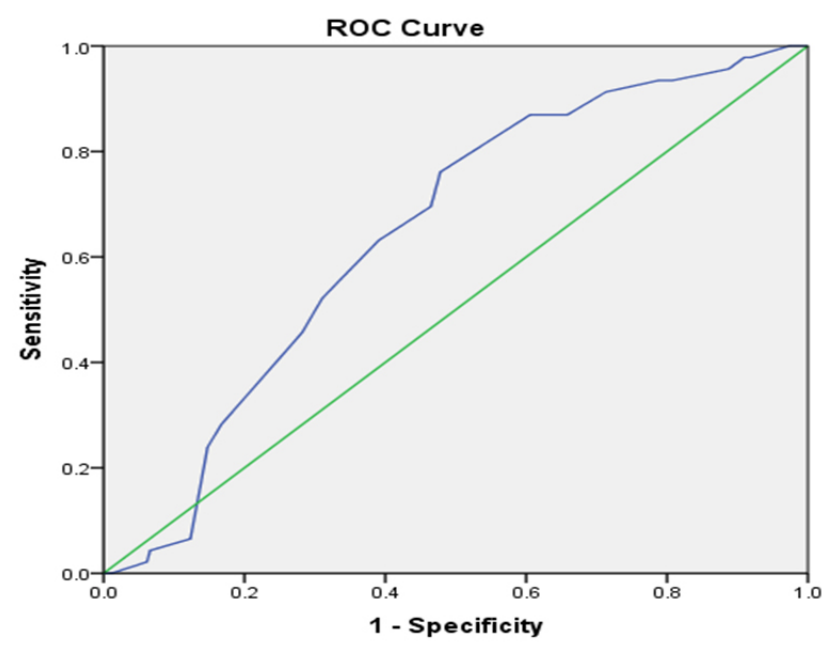

Diagonal segments are produced by ties.

Figure 1. ROC Curve

The AUC for all of the units collectively was 0.647 (95\% CI

$0.575-0.719, p<.05)$ showing a poor balance between sensitivity and specificity.

Surveys regarding the MFS were distributed to 10 nurses on the CQI council and seven responded. Positive comments were that the MFS was useful - "Yes I think the MFS is useful but it is not always taken seriously". Nurses felt the MFS needed to be revised and more education was needed for staff on fall prevention. Themes with staff comments are illustrated in Table 4. Within these data, two major themes were identified: Change or adjustment of the screening tool and Education.

Published by Sciedu Press

\section{Discussion}

The purpose of this study was to test the predictive validity of the MFS by assessing the values of sensitivity, specificity, PPV, NPV and cut-off score on the medicine units in an acute care hospital. Predictive validity shows the ability of the MFS to discriminate between patients with an increased risk of falling versus patients with a low risk. Using the cut-off of 25, the screening tool's sensitivity was high (98\%), however, the specificity was very low $(8 \%)$. One reason for a low specificity can be that patients who were deemed high risk did not fall because of the effective preventative strategies that were put in place. A consequence though of the low cut-off point is that most patients were deemed high risk which could lead to the adoption of inappropriate fall prevention strategies. Only $7.2 \%$ of patients were rated as low risk for the Medicine Program. This meant that many patients may have been receiving unnecessary and costly advanced high risk interventions such as bed and chair alarms along with increased observation. Hospital administrators must determine the optimal sensitivity and specificity values that are acceptable for a given patient population. For example, units with rehabilitation and increased mobility goals may choose to tolerate a more modest sensitivity and specificity value in order to be less restrictive. According to the findings, the optimal cut-off point for the MFS in this setting is 55 (sensitivity $=87 \%$, specificity $=34 \%$ ) as opposed to 25 (sensitivity $=98 \%$, specificity $=8 \%)$ the point currently used. This supports a study conducted by Healey and Haines ${ }^{[28]}$ who found 55 to be more useful in a similar hospital setting. 
To help determine the optimal cut-off point, a ROC analysis was conducted. The AUC was 0.647 which illustrates the relationship between the sensitivity and the specificity of the screening tool. A result around 0.5 would indicate a lack of accuracy for this tool ${ }^{[32,34]}$ signifying that this tool had only moderate accuracy. Fall prevention strategies such as implementing a falls risk screening tool are meant to reduce patient falls. Risk assessment is supposed to be used to separate the high risk fallers from the low risk fallers so that limited resources can be applied to those most in need. An inadequate screening tool and/or cut-off point can result in unnecessary targeted interventions which impose a burden on staff time and hospital costs. By conducting a validity analysis of a falls risk screening tool, hospital administrators can examine the results and determine an acceptable sensitivity and specificity balance.

As a follow-up to the findings of this study, a question was posed to the nurses on the CQI council to elicit feedback on the MFS screening tool. They were asked whether or not they thought screening tools are effective for assessing the risk for falls? The survey went to medicine nurses on the CQI council who regularly fill out the MFS as part of their nursing practice. Positive comments came back indicating that the tool was helpful for awareness and for implementing appropriate strategies. However, there were two main areas that the nurses wanted addressed (see Table 4): (1) change the screening tool; (2) provide more education to staff around fall risks and prevention.

In regards to changing the tool, one recommendation was to change the cut-off point. Another was to consider using a different screening tool. For a screening tool to be effective it needs predictive validity, easy completion, short minimal training, and high sustainability. ${ }^{[35]}$ The STRATIFY and the Hendrich II are two screening tools that have been validated in similar settings. ${ }^{[36]}$ However, any screening tool still needs to be validated for the setting in which it is to be utilized. ${ }^{[14,37]}$ The workload for nursing staff can be decreased when using an appropriate assessment tool. Staff can be inundated with medical forms to complete during the admission process.

Staff workload ratios need to be considered as well since documentation takes time away from patient care. Nurses spend approximately $25 \%$ of their time completing forms in the hospital. ${ }^{[38]}$ The general ratio levels in this area were four patients to one nurse during the day (7:00 a.m. - 7:00 p.m.) and six patients to one nurse at night (7:00 p.m. 7:00 a.m.). According to anecdotal narratives by nurses, this "does not leave room for unpredictable patient behaviours" which can lead to falls. Staff-patient ratios are based on acuity measurement indicators which administrators review regularly to help determine staffing levels. ${ }^{[26]}$ Alternative nursing patterns should be explored during busy times on the unit. A fall risk screening tool has to be used as part of a larger fall prevention program and it should not replace a more thorough individualized clinical assessment and the need for additional resources to reduce falls.

Another area nurses wanted to address was more education. This is incorporated with the second recommendation which was to remove the screening tool from the hospital's fall prevention program. This would lead to staff needing additional training to identify risks. This extra education could be a burden to hospital resources. There are also other implications when removing a validated screening tool. It can be time consuming for all interdisciplinary staff members that need to be involved. For example, physiotherapists would have to be consulted to assess mobility and gait early in the admission process and pharmacists would have to evaluate the amount of medication that can potentially lead to a fall. Currently program pharmacists verify medications ordered but there is no protocol which looks at identifying high fall risk medications. ${ }^{[39]}$ Finally, the loss of a standardized screening tool could result in inconsistent documentation. This is particularly important to the Risk Management department and the accreditation quality assurance bodies that look to documentation for proof of "due diligence" care by staff. These factors need to be considered when devising a fall prevention program.

The premise of a screening tool is to score the risks on a regular basis and implement strategies to reverse the risk factors thereby reducing the score and risk level. Opponents say each case should be treated individually in order to look for reversible risk factors on all patients, ${ }^{[40]}$ or concentrate on capturing recurrent fallers and focus more on post fall assessment and interventions. Ganz et al. ${ }^{[41]}$ searched the literature and determined that having a previous fall (within one year) and having problems with gait or balance put patients at high risk. They suggested that clinicians identify particular patient attributes that can predict falls and then implement effective multifactorial interventions. In a study by Healey et al. ${ }^{[42]}$ the authors developed a falls reduction program with elderly patients in a general hospital. A care plan was adopted for patients in order to target individual fall risk factors. Risk factors were identified through a general patient assessment and appropriate interventions were applied to reduce falls. The result was a positive reduction in falls. A study by Myers \& Nikoletti ${ }^{[34]}$ compared the use of a risk assessment on admission versus a risk assessment on patients placed on a fall risk care plan. Their research showed there was no significant difference between patients 
who had fallen and those who had not. For this to be successful enough resources need to be in place. The combination of older adults with high acuity and multiple co-morbidities put more demand on nurses and makes it difficult to be at the bedside supervising patients as they transferred, for example, to the bathroom. ${ }^{[4]}$ To manage resources better the types of falls in hospitals have to be evaluated as well.

When developing the MFS three types of falls were proposed by Morse et al. ${ }^{[44]}$ In the hospital setting the most prevalent type was "physiological anticipated" falls which were the type identified by the MFS. The authors found that this kind of fall made up $78 \%$ of hospital falls. These falls were related to impaired gait, use of walking aids and patients who were intermittently confused. These falls call for immediate preventative measures such as increased supervision and assistance when ambulating. "Physiological unanticipated" refer to falls related to dizziness and fainting. These occur $8 \%$ of the time in hospitals. Interventions should include patient teaching on the disease process and medication reactions. "Accidental" falls can result from tripping over obstacles or slippery floors. These occur $14 \%$ of the time. Adjusting the environment such as providing proper lighting and flooring could prevent these types of falls. Being educated on the three types of falls that occur in hospitals, along with implementation of prevention strategies, allows staff to modify their care to prevent a fall.

\section{Study strengths and limitations}

There are limitations to this study. Firstly, the scope of the findings was confined to the inpatient medicine units in the hospital. Further research needs to be conducted in multiple programs in order to generalize the results across the entire hospital. Secondly, although the CQI council was representative of the nurses on the units, only some views on the MFS were captured. Interviewing more nurses would have provided greater insight concerning the use of the MFS in clinical practice. This study did inform the hospital of the advisability of adopting a more effective cut-off point for risk assessment. In a broad sense, this study will generate evidence-based data to assist other organizations considering the implementation of a falls risk screening tool.

\section{Conclusion}

In summation, if a fall risk screening tool is preferred as part of a hospital's fall prevention program, a predictive validity analysis should be conducted prior to its full adoption. A reasonable cut-off score needs to be identified according to the setting with a predetermined balance between sensitivity and specificity. This would deliver a more accurate fall risk score and off-load some of the unnecessary burden nurses face on a daily basis. If contemplating a fall prevention program without the use of a screening tool, an individualized care plan needs to be in place with clear follow-up guidelines and interventions. Interdisciplinary staff would require education on all aspects of patient falls. Even though there are limitations, there is an advantage in a large sample size used in the study as well as delivering practical recommendations aimed at reducing patient falls.

\section{REFERENCES}

[1] Aranda-Gallardo M, Morales-Asencio JM, Canca-Sanchez JC, et al. Instruments for assessing the risk of falls in acute hospitalized patients: A systematic review and meta-analysis. BMC Health Services Research. 2013; 13(122): 1-15. http://dx.doi.org/10.1186/1 472-6963-13-122

[2] Accreditation Canada. Safety in Canada health care organizations: A focus on transitions in care and required organizational practices. Canadian Health Accreditation Report. 2015; 1-24.

[3] Safer Healthcare Now. Getting started kit: Reducing falls and injuries from falls. 2015. Available from: www. saferhealthcarenow.ca

[4] Registered Nurses Association of Ontario. Prevention of falls and fall injuries in the older adult. 2002. Available from: http://rnao.ca

[5] Oliver D, Healey F, Haines TP. Preventing falls and fall-related injuries in hospitals. Clinics in Geriatric Medicine. 2010; 26(4): 645-92. PMid: 20934615. http://dx.doi.org/10.1016/j.cger. 2010 .06 .005

[6] Currie L. Fall and Injury Prevention. Patient Safety and Quality: An Evidenced-Based Handbook for Nurse (Hughes, R.G. Ed). Rockville, MD: Agency for Healthcare Research and Quality; 2008.
[7] Krauss MJ, Tutlam N, Costantinou E, et al. Intervention to prevent falls on the medical service in a teaching hospital. Infection Control and Hospital Epidemiology. 2008; 29(6): 539-545. PMid: 18476777. http://dx.doi.org/10.1086/588222

[8] Rubenstein LZ. Falls in older people: Epidemiology, risk factors and strategies for prevention. Age and Ageing. 2006; 35(S2): 37-41. http://dx.doi.org/10.1093/ageing/af1084

[9] Schwendimann R, De Geest S, Milisen K. Screening older patients at risk for falling during hospitalization. International Journal of Injury Control and Safety Promotion. 2007; 14(1): 64-65. PMid: 17624015. http://dx.doi.org/10.1080/17457300600775536

[10] World Health Organization. Geriatric giants-current issues and challenges. The Ageing Congress. 2012.

[11] Oliver D. Assessing the risk of falls in hospitals: Time for a rethink? Canadian Journal of Nursing Research. 2006; 38(2): 89-94. PMid: 16871852.

[12] Hendrich AL, Bender PS, Nyhuis A. Validation of the Hendrich II Fall Risk Model: A Large Concurrent Case/Control Study of Hospitalized Patients. Applied Nursing Research. 2002; 16(1): 9-21. http://dx.doi.org/10.1053/apnr.2003.016009 
[13] Vieira ER, Berean C, Paches D, et al. Reducing falls among geriatric rehabilitation patients: A controlled clinical trial. Clinical Rehabilitation. 2012; 27(4): 325-335. PMid: 22952303. http: //dx.doi.org/10.1177/0269215512456308

[14] Scott V, Votova K, Scanlan A, et al. Multifactorial and functional mobility assessment tools for fall risk among older adults in community, home-support, long-term and acute care setting. Age and Ageing. 2007; 36(2): 130-139. PMid: 17293604. http://dx.doi.org/10. 1093/ageing/afl165

[15] Baek S, Piao J, Jin Y, et al. Validity of the Morse Fall Scale implemented in an electronic medical record system. Journal of Clinical Nursing. 2013; 23: 2434-2441. PMid: 24112535. http: //dx.doi.org/10.1111/jocn.12359

[16] Morse JM. Preventing patient falls: Establishing a fall intervention program (2nd Ed.) New York: Springer Publishing Company; 2009.

[17] National Institute for Health and Care Excellence. Falls in older people: Assessing risk and prevention. NICE Guidelines. 2013. Available from: http://www.nice.org

[18] Chelly JE, Conroy L, Miller G, et al. Risk factors and injury associated with falls in elderly hospitalized patients in a community hospital. Journal of Patient Safety. 2008; 4(3): 178-183. http: //dx.doi.org/10.1097/PTS.0b013e3181841802

[19] Morse JM, Morse RM, Tylko SJ. Development of a scale to identify the fall-prone patient. Canadian Journal an Aging. 1989; 8(4): 366-375. http://dx.doi.org/10.1017/S0714980800008576

[20] Morse JM, Black C, Oberle K, et al. A prospective study to identify the fall-prone patient. Social Science and Medicine. 1989; 28(1): 8186. http://dx.doi.org/10.1016/0277-9536(89)90309-2

[21] Ang NKE, Mordiffi SZ, Wong HB, et al. Evaluation of three fall-risk assessment tools in an acute care setting. Journal of Advanced Nursing. 2007; 60(4): 427-435. PMid: 17919164. http: //dx.doi.org/10.1111/j.1365-2648.2007.04419.x

[22] Hendrich AL, Bender PS, Nyhuis A. Validation of the Hendrich II fall risk model: A large concurrent case/control study of hospitalized patients. Applied Nursing Research. 2003; 16(1): 9-21. PMid: 12624858. http://dx.doi.org/10.1053/apnr.2003.016009

[23] Oliver D, Britton M, Seed P, et al. Development and evaluation of evidence based risk assessment tool (STRATIFY) to predict which elderly inpatients will fall: Case- control and cohort studies. British Medical Journal. 1997; 315: 1049-1053. PMid: 9366729. http://dx.doi.org/10.1136/bmj .315.7115.1049

[24] Spoelstra SL, Given BA, Given CW. Fall prevention 2012 in hospitals: An integrative review, Clinical Nursing Research. 2012; 21(1): 92-112. PMid: 21862700. http://dx.doi.org/10.1177/10547 73811418106

[25] Lincoln YS, Guba EG. Naturalistic Inquiry. London: Sage Publications; 1985.

[26] Watson BJ, Salmoni AW, Zecevic AA. Falls in an acute care hospital as reported in the adverse event management system. Journal of Hospital Administration. 2015; 4(4): 84-91. http://dx.doi .org/10 $5430 / j h a . v 4 n 4 p 84$

[27] World Health Organization. Global report on falls prevention in older age. 2007. Available from: http://www.who.int/ageing/pub lications/Falls_prevention7March.pdf

[28] Healey F, Haines TP. A pragmatic study of the predictive values of the Morse falls score. Age and Ageing. 2013; 42(4): 462-468. PMid: 23669562. http://dx.doi.org/10.1093/ageing/aft049
[29] International Business Machines Corporation. Statistical Package for the Social Sciences Statistics forWindows, Version 22.0. Armonk, New York: IBM Corporation; 2013.

[30] Walsh W, Hills KD, Bennell K, et al. Local adaptation and evaluation of a falls risk prevention approach in acute hospitals. International Journal for Quality in Health Care. 2011; 23(2): 134-141. PMid: 21131384. http://dx.doi.org/10.1093/intqhc/mzq075

[31] Thompson C, Dowding D. Clinical decision making and judgement in nursing. New York: Churchill Livingstone; 2002.

[32] Hajian-Tilaki K. Receiver operating characteristic (ROC) curve analysis for medical diagnostic test evaluation. Caspian Journal of Internal Medicine. 2013; 4(2): 627-635. PMid: 24009950.

[33] Fawcett T. An introduction to ROC analysis. Pattern Recognition Letters. 2006; 27(8): 861-874. http://dx.doi.org/10.1016/j .patrec.2005.10.010

[34] Myers H, Nikoletti S. Fall risk assessment: A prospective investigation of nurses' clinical judgement and risk assessment tools in predicting patient falls. International Journal of Nursing Practice. 2003; 9(3): 158-165. PMid: 12801247. http://dx.doi.org/10. 1046/j.1440-172X.2003.00409.x

[35] Oliver D, Healey F. Falls risk prediction tools for hospital inpatients: Do they work. Nursing Times. 2009; 105(7): 18-21. PMid: 19326648

[36] Heinze C, Dassen T, Halfens R, et al. Screening the risk of falls: A general or a specific instrument? Journal Clinical Nursing. 2008; 18: 350-356. PMid: 18702621. http://dx.doi.org/10.1111/j .1365-2702.2008.02453.x

[37] McFarlane-Kolb H. Falls risk assessment, multi-targeted interventions and the impact on hospital falls. International Journal of Nursing Practice. 2004; 10: 199-106. PMid: 15461689. http: //dx.doi.org/10.1111/j.1440-172X.2004.00482.x

[38] Trossmann $S$. The documentation dilemma: Nurses poised to address paperwork burden. Tar Heel Nurse. 2002; 6(3): 10-11.

[39] Frels C, Williams P, Narayanan S, et al. Iatrogenic causes of falls in hospitalized elderly patients: A case-control study. Postgraduate Medical Journal. 2002; 78: 487-489. PMid: 12185225. http: //dx.doi.org/10.1136/pmj.78.922.487

[40] Coussement J, De Paepe L, Schwendimann R, et al. Interventions for preventing falls in acute-and chronic-care hospitals: A systematic review and meta analysis. Journal of the American Geriatrics Society. 2008; 56: 29-36. PMid: 18031484. http://dx.doi.org/10.11 $11 / j .1532-5415.2007 .01508 . x$

[41] Ganz DA, Bao Y, Shekelle PG, et al. Will my patient fall? The Journal of the America Medical Association. 2007; 297(1):77-86. PMid: 17200478. http://dx.doi.org/10.1001/jama.297.1.77

[42] Healey F, Monro A, Cockram A, et al. Using targeted risk factor reduction to prevent falls in older in-patients: A randomized controlled trial. Age and Ageing. 2004; 33 (4): 390-395. PMid: 15151914 http://dx.doi.org/10.1093/ageing/afh130

[43] Hendrich AL. Inpatient Falls: Lessons from the field. Patient Safety \& Quality Healthcare. 2006.

[44] Morse JM, Tylko SJ, Dixon HA. Characteristics of the fall-prone patient. The Gerontological Society of America. 1987; 27(4): 516-522. http://dx.doi.org/10.1093/geront/27.4.516 